\title{
Activity of Extreme Environmental Factors as a Reason for Pink Salmon Abundance Decline in the Sakhalin-Kuril Region, Russia
}

\author{
Alexander M. Kaev \\ Sakhalin Research Institute of Fisheries and Oceanography (SakhNIRO), 196, Komsomolskaya Str., Yuzhno- \\ Sakhalinsk, 693023, Russia
}

Keywords: Sakhalin Island, Iturup Island, pink salmon, abundance, extreme factors (floods, storms in sea coasts)

Some changes in pink salmon abundance from 2007-2017 have been studied on Iturup Island and four areas of the eastern Sakhalin coast. An abrupt decline in abundance was observed in broodlines which appeared to be due to the influence of extreme environmental factors. The extreme events were both the floods caused by abnormal high precipitation that destroyed spawning grounds, and the storms on the seacoast during the mass fry downstream migrations to the sea. Estimated run sizes of pink salmon in 2017 in the monitored areas fully agreed with the ascertained dependences for the preceding period. These results show a decisive role of extreme environmental factors in pink salmon abundance formation.

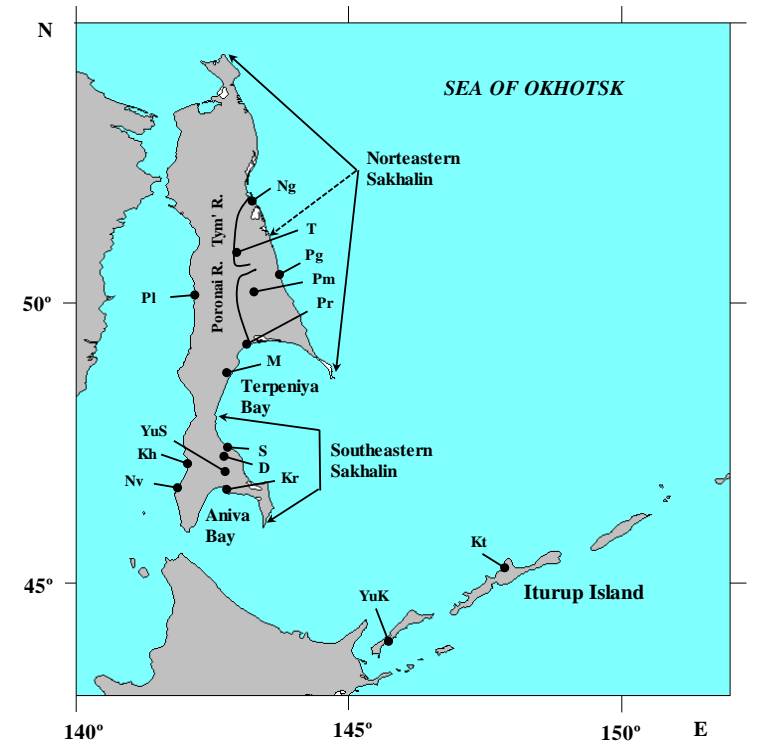

Fig. 1. The main areas of pink salmon fisheries in the Sakhalin-Kuril region and sites of meteorological observations: YuK-Yuzhno-Kurilsk, Kt-Kitovoye, NvNevelsk, Kh-Kholmsk, Pl-Pil'vo, Kr-Korsakov, YuSYuzhno-Sakhalinsk, D-Dolinsk, S- Starodubskoye, MMakarov, Pr-Poronaysk, Pm- Pervomaisk, Pg-

Pogranichnoye, $\mathrm{T}-$ Tymovskoye, $\mathrm{Ng}-\mathrm{Nogliki}$.
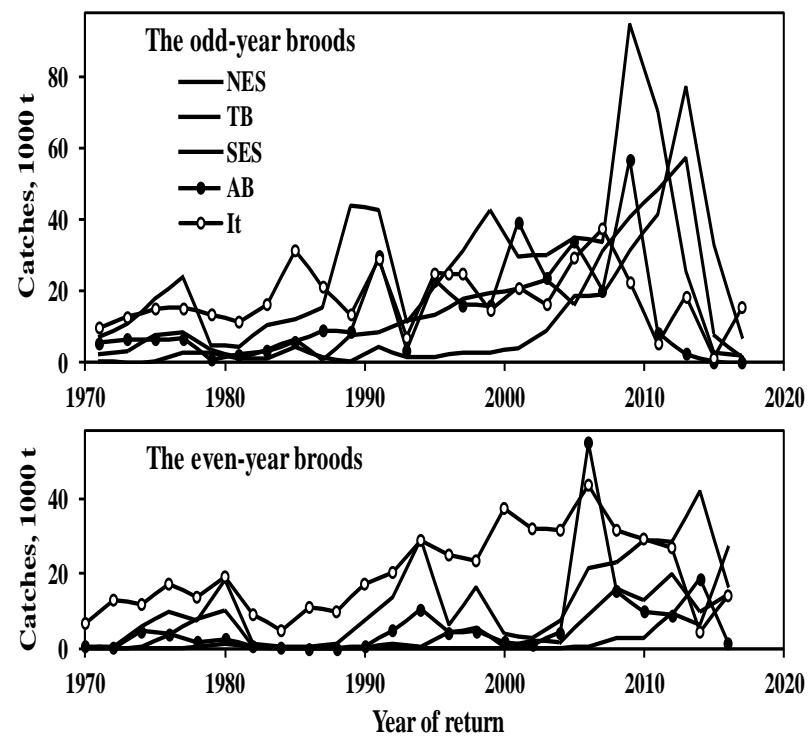

Fig. 2. Dynamics of pink salmon catch in certain areas of the Sakhalin-Kuril region from 1970-2017: NESnortheastern Sakhalin, TB-Terpeniya Bay, SESsoutheastern Sakhalin, AB-Aniva Bay, It-Iturup Island.

The Sakhalin-Kuril region possesses about half of the Russian catches of pink salmon, so prospective changes in its abundance are a subject of the high interest. About $90 \%$ of pink salmon are captured in the four areas of eastern Sakhalin and Iturup Island (Fig. 1). Beginning from 1970, the average annual catch was 18,981 metric tons on Iturup Island, 10,090 metric tons in Aniva Bay, 19,123 metric tons in southeastern Sakhalin, 10,112 metric tons in Terpeniya Bay, and 6,686 metric tons in northeastern Sakhalin. Also, since 1970, this catch trend has changed substantially in different years and areas (Fig. 2).

A significant decline in catches in the even-numbered years had been observed everywhere in the 1980s, while in the mid of that 10-year period the catches increased in the odd-numbered years. After a short-term decline in 1993, catches in eastern Sakhalin tended to increase in odd-numbered years, and increase on Iturup Island in evennumbered years where the dominants had changed. In the last 10 years, both pink salmon broodlines have reached 
historical maximum of catches. At the same time, increases and/or decreases in catch rates differed by areas, and their peaks and falls were not strictly synchronous in the different areas. Such a mismatch is noticeable for the last 10-year period. The maximum catches were prematurely taken in southern areas, and the decrease in catches for dominant broodlines started ahead of time in the same areas (Iturup Island and Aniva Bay). In May 2015, a hypothesis about the forthcoming significant decline in catches of northern part of eastern Sakhalin (Kaev 2015) was reported at the NPAFC International Symposium on Pacific Salmon and Steelhead Production in a Changing Climate: Past, Present, and Future taking place in Kobe (Japan). Later in 2015, that event had actually happened.

There is an uncertainty surrounding the reasons for such abrupt and time-unmatched declines in pink salmon catches in neighboring areas. Previous work has shown that the mean statistic values of the environmental parameters cannot be used for predicting such changes in pink salmon abundance. The reason behind this is that fish populations have certain resistance to environment fluctuations. So, significant changes in their abundances should occur, to a greater extent, because of the casual (rare, unusual) environmental factors (Kaev 1989; Kriksunov 1995). Both the abnormal high autumn floods that destroy grounds on the spawning areas (Kaev 1983; Putivkin 1989; Kaev and Chupakhin 2003), and sea storms that strongly affect the fry recently migrated downstream (Kaev 1992) should be related to these factors for the first turn. To examine this hypothesis, we used the data of meteorological stations on numbers of precipitation and strength of winds (https://rp5.ru, the data are at the disposal since 2005), which were correlated with the abundance of pink salmon of the corresponding broodlines.

The probability of the rain floods in rivers was determined based on the maximum sum of precipitation during the two days adjacent to the precipitation event. Since the precipitations' falling is uneven over the vast territory, to characterize their numbers on each of the reproduction areas for pink salmon stocks studied, we tried to use the data of several meteorological stations (Fig. 1). Thus, for the Aniva Bay pink salmon, most of which spawn in rivers of western and northwestern coasts of the bay, the calculation was completed using the data obtained from stations located in Yuzhno-Sakhalinsk, Kholmsk and Nevelsk. For southeastern Sakhalin pink salmon, which spawning grounds are mainly concentrated in rivers of northern part of the area, the calculation was completed using the data of Yuzhno-Sakhalinsk and Dolinsk stations. For the Terpeniya Bay pink salmon, about half of which spawn in mountain rivers of western coast of the bay, and another part in the basin of Poronai River and adjacent rivers of the vast lowland, the calculation was completed using the data of Makarov, Pil'vo, Poronaisk, Pervomaisk, and Pogranichnoye stations. For northeastern Sakhalin pink salmon, whose percentage in commercial catches is $75 \%$ due to the fish spawning in mountain rivers of southern part, the calculation was completed using the data of Pervomaisk, Pogranichnoye, and Tymovsk stations. On Iturup Island the calculation was completed using the data of the only station in Kitovoye, which is located in the center of the most productive spawning areas for a local pink salmon stock. We used the extreme values of precipitation exceeding $8 \mathrm{~cm}$ for Iturup Island, $6 \mathrm{~cm}$ for southern Sakhalin with its larger rivers, and $5 \mathrm{~cm}$ for the large rivers of northern Sakhalin.

A probability of the storm conditions in the sea coastal zone was determined based on the average value of the maximum wind gusts fixed during four to eight daily measurements. The data from Korsakov and YuzhnoSakhalinsk stations was used for Aniva Bay, the data from Yuzhno-Sakhalinsk and Starodubsk stations was used for southeastern Sakhalin, the data from Makarov and Poronaisk stations was used for Terpeniya Bay, the data from Pogranichniy and Nogliki stations was used for northeastern Sakhalin, and the data from Kitovoye station was used for Iturup Island. In the years when observations for wind strength (2016) and amount of precipitation (2015-2016) were not carried out at Kitovoye station, the data of Yuzhno-Kurilsk station (Kunashir Island) was used for Iturup Island. The mean daily values exceeding $16 \mathrm{~m} / \mathrm{s}$ were used as extreme values, except on Iturup Island where mean daily values exceeding $17 \mathrm{~m} / \mathrm{s}$ were used because there are more shelters for juveniles due to the shoreline architecture of the island.

When analyzing the influence of these factors on pink salmon abundance, we should take into account the following circumstances. The proportion of hatchery-reared fish among the downstream migrating juveniles was 30-58\% for the Iturup pink salmon broodlines, 17-66\% for the southern part of east Sakhalin, 3-25\% for Terpeniya Bay, and in northeastern Sakhalin practically all of the juveniles which migrated downstream were from spawning grounds. If in seawater, the environmental factors simultaneously affect hatchery-reared and wild fish, then in rivers the destructive action of floods will affect the products of spawning. To avoid such an imbalance, we have analyzed abundance changes only in wild fish. Fish caught were conditionally divided into wild and hatchery-reared individuals according to the ratio of numbers of fry migrated downstream from spawning areas, and those released from hatcheries; assuming they were following equal survival in seawaters. The number of fish counted in rivers on spawning grounds was added to the obtained number of wild fish captured.

Second, we took into account the timing of extreme factors, when they could cause most damage to pink salmon reproduction: floods - in the second half of the mass spawning or after its completion-and storms in the 
period of mass fry downstream migration from rivers. To increase perception of timing of their actions, each year fragment on the x-coordinate includes a conditional range of time interval between August and November (for precipitation), and between 1 May and 10 July (for wind) (Fig. 3).
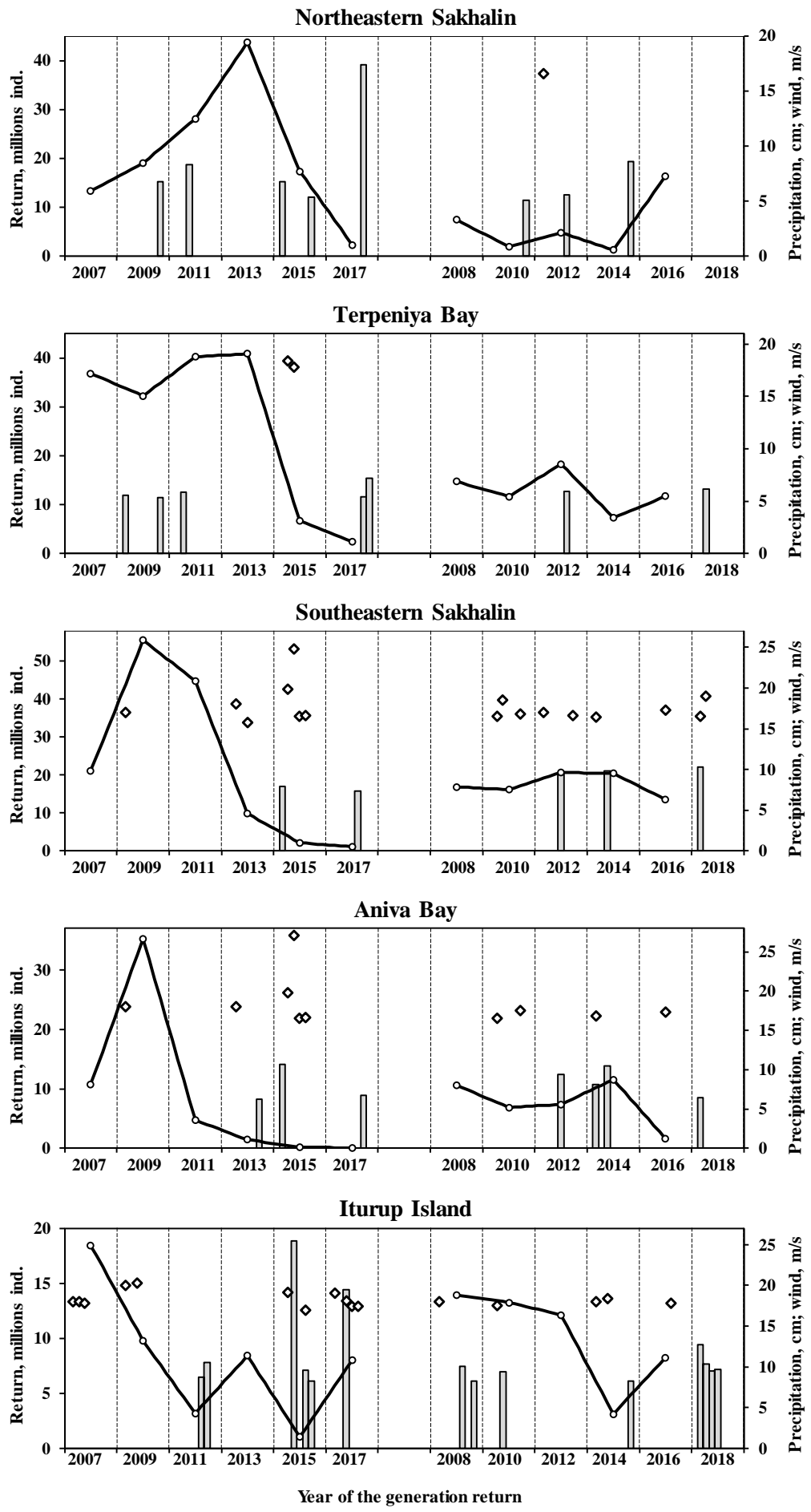

Fig. 3. Dynamics of pink salmon abundance, by odd and even broodlines (lines), number of the days with extremely high precipitation during its spawning and soon after the spawning (columns), and number of the days with strong wind during its juveniles feeding in the coastal sea (symbols). 
Declines in abundance for pink salmon broodlines strongly affected by the extreme environmental factors were registered in all areas. The low-abundant returns of pink salmon in 2011 in Aniva Bay and the comparatively high-abundant returns in 2008 on Iturup Island are not exclusions. In the first case, the decline in abundance was caused by a strong flood in rivers flowing from the mountain ridge of western coast of Aniva Bay where the main part of pink salmon stock spawned in recent years. The flood in the second half of September was proved by the witness, fisherman K. Mitaki, and by the records of meteorological stations stated the increase in precipitation number on 18-19 September ("Nevelsk", $3.6 \mathrm{~cm}$; "Kholmsk", $4.7 \mathrm{~cm}$ ); the cardinal rain front could pass along the ridge from the bay side. In the second case pink salmon abundance in 2008 on Iturup Island, though comparatively high for the considered year series, decreased 1.5 times in comparison with the parent generation.

In 2015, the minimum number of adults returned to Iturup Island was caused by floods during the mass spawning process and by a storm during the period of the mass fry downstream migration. The decline in pink salmon abundance in Aniva Bay and southeastern Sakhalin in 2015 was caused by storms during the period of the mass fry downstream migration. In Terpeniya Bay and northeastern Sakhalin a decline in pink salmon abundance in 2015 was not very large because storm winds in the first area affected only the early migrated juveniles, and a flood in rivers of the second area after spawning completion was not very strong.

Based on the results of these studies we suggested that in 2017 the pink salmon abundance in southern areas of the region would remain low, and in northern areas, significant decline would be inevitable because of the record high autumn precipitation (Kaev 2018). This scenario was fully realized in eastern Sakhalin, but on Iturup Island, at first glance, the prediction was not true. Nevertheless, an unfavorable impact of extreme factors on abundance formation of this broodline took place which was proved by the dynamics of pink salmon catches in 2017. Catches in the first half of the pink salmon run were lower than the mean of preceding odd years (Fig. 4), that corresponds to both the flood passing in the middle of the spawning process of their parents, and the storms observed in the first half of the mass fry downstream migration to the seacoast. Besides, the impact of these factors on Iturup pink salmon cannot be considered very significant as the meteorological data of neighboring Kunashir Island was used to characterize spawning conditions for this broodline; due to the absence of corresponding data on Iturup Island.

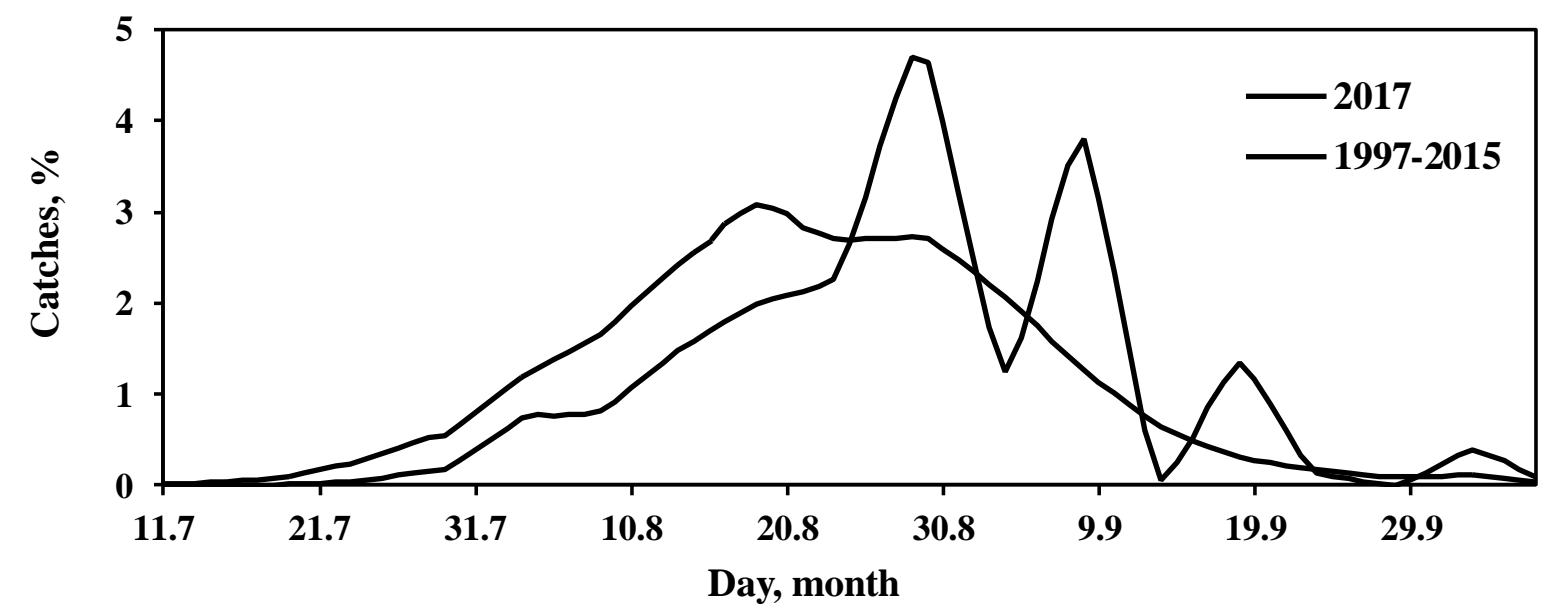

Fig. 4. Seasonal dynamics of pink salmon catch on Iturup Island in 2017 compared with the mean dynamics for preceding odd years.

The maximum values of the considered extreme environmental factors influencing pink salmon reproduction are taken as " 1 " for the mathematic interpretation of their total impact, and for the rest factors, parts are calculated proportionally to their values relative to these maxima. For the broodlines weakly exposed to these factors (before the mass spawning process, and before or after the mass fry downstream migration), their values are taken as " 0 ". Correlation of changes in pink salmon abundance with the values of extreme factors obtained on Iturup Island $(r=-$ $0.70, p=0.015)$, in Aniva Bay $(r=-0.52, p=0.102)$, in Terpeniya Bay $(r=-0.47, p=0.148)$, in southeastern Sakhalin $(r=-0.51, p=0.106)$, and in northeastern Sakhalin $(r=-0.52, p=0.104)$ are statistically uncertain in most cases that are associated with a short series of observations (an objectivity of the occurring processes is evident). The situation is enhanced by the fact that for only four-six of 11 generations studied in each area, the values of extreme factors were variable, in the rest of the cases they were taken as " 0 ". 
The trajectory and power of each of the cyclones are specific and produce local foci of their influence on pink salmon reproduction in the area. For example, in 2011 the decline in pink salmon abundance occurred in Aniva Bay due to the flood in rivers on its western coast, whereas the abundance of pink salmon in southeastern Sakhalin remained at a high level. In 2013, there was a decline in abundance in these both areas, but its genesis differed: a decline in abundance in Aniva Bay was caused by the impact of the autumn river flood on spawning process, and on southeastern coast it was caused by the impact of storms on the recently migrated fry. But even if the timing series of environmental factors coincides, this does not always lead to similar results. Thus, the dates with strong winds in Aniva Bay and southeastern Sakhalin coast often concurred, however, they did not equally affect the formation of pink salmon abundance in these areas because of different timing of fry migrations (Kaev 2018). When reporting regional characteristics of the negative cyclonic impact on pink salmon reproduction, we should also note that in southern areas this impact was mainly manifested through the storms in the juvenile feeding period, and in northern areas it manifested through the soil erosion on spawning grounds during floods.

Thus, a decline of pink salmon abundance in broodlines appeared under the impact of strong cyclones during fish embryonal development in rivers (destruction of redds) or in the period of mass fry migration to seawaters, allowing us to suggest their significant importance for abundance formation of this species. The appearance of lowharvest broodlines series was observed to coincide by time with the change of warm zonal and cold meridian epochs which have been observed in the 1980s and hypothetically occur in the contemporary period (Kotenev et al. 2012, 2015). Perhaps, a change of these epochs is accompanied by the shift of trajectories and dates of cyclones passing. So, in these years the probability of their negative impact on pink salmon reproduction increases, resulting in a series of the low-harvest broodlines. At the same time the typhoons' strength and limits of their impact vary continuously that explains the appearance of local characteristics for pink salmon changes in abundance in the region.

\section{REFERENCES}

Kaev, A.M. 1983. Development of population of autumn chum salmon Oncorhynchus keta (Walbaum) (Salmonidae) of Sakhalin and Iturup Island. Vopr. Ikhtiol. 23(1): 45-52. (In Russian)

Kaev, A.M. 1989. Some methodological aspects of prospective populations of chum and pink salmons. Biol. Morya (Vladivostok) 2: 61-66. (In Russian)

Kaev, A.M. 1992. The risk group of juveniles of chum salmon Oncorhynchus keta during fatting in estuary. Vopr. Ikhtiol. 32(2): 53-60. (In Russian)

Kaev, A. M. 2015. Status of pink salmon in the Sakhalin-Kuril region in a long-term aspect. Abstract of NPAFC Intern. Symp. "Pacific Salmon and Steelhead Production in a Changing Climate: Past, Present, and Future" (Kobe, May 17-19, 2015), Vancouver: NPAFC, p. 19.

Kaev, A.M. 2018. Influence of extreme environmental factors on the dynamics of abundance of the pink salmon Oncorhynchus gorbuscha. J. Ichthyol. (2): 204-216.

Kaev, A.M., and Chupakhin, V.M. 2003. Dynamics of schools of pink salmon Oncorhynchus gorbuscha of Iturup Island (the Kuril Islands). J. Ichthyol. 43(9): 769-779.

Kotenev, B.N., Krovnin, A.S., Kivva, K.K., et al. 2012. Low frequency of winter climate conditions in northwestern part of Pacific Ocean in 1950-2012. Vopr. Prom. Oceanogr. 9: 33-60. (In Russian)

Kotenev, B.N., Krovnin, A.S., Klovach, N.V., et al. 2015. Influence of climate-oceanological factors on the general stocks of the pink salmon in 1950-2015. Tr. VNIRO, 158: 143-161. (In Russian)

Kriksunov, E.A. 1995. The theory of replenishment and interpretation of the dynamics of fish populations. Vopr. Ikhtiol. 35(3): 302-321. (In Russian)

Putivkin, S.V. 1989. Development of hydrological regime of spawning sites of Anadyr chum salmon. Vopr. Ikhtiol. 29(1): 96-103. (In Russian) 